\title{
О СОВМЕСТИМОСТИ ПРИНЦИПОВ СЛЕДЯЩЕГО КАПИТАЛИЗМА С ОСНОВАМИ ДЕМОКРАТИЧЕСКОГО ОБЩЕСТВА
}

\section{ON THE COMPATIBILITY OF THE PRINCIPLES OF SURVEILLANCE CAPITALISM WITH THE FOUNDATIONS OF A DEMOCRATIC SOCIETY}

\section{A. Klimovich}

Summary: This article analyzes the term of surveillance capitalism proposed by S. Zuboff, and provides a brief description of the causes of the phenomenon indicated by this term. The principles of surveillance capitalism are considered, the mechanisms underlying its basic functioning are examined. The contradictions between the principles of surveillance capitalism and the foundations of a democratic social order are revealed. The procedure of transition from the technique of surveillance and collection of behavioral information to the technique of manipulating social behavior is considered. The topic of the concentration of knowledge and the related emergence of a new type of power - instrumental power is highlighted. The issue of the spread of discursive practices and the influence on them of the processes associated with the development of surveillance capitalism is considered. The main directions of counteraction to the negative effects associated with the onset of the era of surveillance capitalism are presented.

Keywords: surveillance capitalism, behavioral surplus value, instrumental power, big data, artificial intelligence, discursive practices.

\author{
Климович Александр Павлович \\ Финансовый Университет при Правительстве РФ, \\ Липецкий Филиал \\ allexgut@gmail.com
}

Аннотация: В данной работе проводится анализ предложенного Ш. Зубофф термина следящего капитализма, делается краткое изложение причин возникновения явления, обозначенного этим термином. Рассматриваются принципы следящего капитализма и исследуются механизмы, лежащие в основные его функционирования. Выявляются противоречия между принципами наблюдающего капитализма и основами демократического общественного устройства. В статье изучена процедура перехода от техники наблюдения и сбора поведенческой информации к технике манипулирования социальным поведением. Освещена тема связи концентрации знаний с возникновением нового типа инструментальной власти. Рассмотрен вопрос распространения дискурсивных практик и влияния на них процессов, связанных с развитием наблюдающего капитализма. Выводятся направления противодействия негативным эффектам, связанным с наступлением эпохи следящего капитализма.

Ключевые слова: следящий капитализм, поведенческая прибавочная стоимость, инструментальная власть, большие данные, искусственный интеллект, дискурсивные практики.

\section{Кремниевая молина}

Д ля понимания феномена успеха Кремниевой долины прежде всего следует рассмотреть пример компании Google, которая наиболее точно отрасуть технологических преобразований, приведших современный мир к глобальной цифровой трансформации. Всего за несколько лет Google из небольшого стартапа превратился в цифрового гиганта, влияние которого очень скоро вышло за рамки технического новаторства и отразилось в экономическом, политическом, научном и культурном измерениях. С самого начала основателями была заявлена амбициозная миссия - «организация мировой информации, обеспечение её доступности и пользы для всех». [1] Организаторы компании обращали внимание не только на техническую сторону продукта, но и на важность взаимодействия с обществом. Это определило высокие стандарты корпоративной этики внутри компании, а также и ее имидж в публичном пространстве. B 2011 году Google была признана компанией с наилучшей репутацией в США, опередив Microsoft, Sony и другие компании. Однако секрет успеха компании был обусловлен не новым корпоративным стандартом и даже не разработкой уникальных технических решений, которые, безусловно, имели место. Решающим фактором, благодаря которому удалось опередить конкурентов, стало открытие новой экономической модели развития. Руководству компании удалось применить принципиально иную логику, отличную от той, что лежала в основе классической модели капитализма 20 столетия. Так ознаменовалось начало новой экономической эры, которую американская исследовательница, экономист, Шошона Зубофф назвала эрой следящего или наблюдающего капитализма (Surveillance capitalism). [2]

Каждая новая экономическая логика и ее коммерческая модель обнаруживаются в определенное время в определенном месте, затем, распространяясь, совершенствуется в процессе применения на практике. Изобретение массового производства в начале 20 века позволило уменьшить себестоимость продукта и обеспечить его доступность и широкомасштабный спрос. Классическим примером применения такой логики 
было открытие массового производства автомобилей. В результате оптимизации процесса цена автомобиля была снижена настолько, что всего трехмесячной зарплаты рядового рабочего завода Форд было достаточно, чтобы приобрести собираемую им на этом заводе Т-Модель. [3] Низкая цена привела к рекордному спросу, сделав эту модель самым продаваемым автомобилем в мире. Менее чем за 10 лет с заводских конвейеров в США сошло более 15 млн. экземпляров. [4] Открытие Фордизма и Тейлеризма стало образцом внедрения новой экономической логики, сформировавшей капитализм массового производства 20 столетия. Подобным образом в начале 21 века в Кремниевой долине была открыта экономическая логика, потеснившая классический принцип массового производства с вершины олимпа прибыльности. Построенная на производстве продукта, основанного на сборе данных, эта логика легла в основу бизнес модели компании Google, ставшей пионером эпохи следящего капитализма.

В интервью Джону Нотону из издания «Гардиан» Зубофф назвала 2001 год, годом, когда был изобретен наблюдающий капитализм. По ее словам, именно тогда началась точка отчета новой эпохи. Поначалу предложенная руководством компании модель в первую очередь решала проблему потери доверия акционеров, возникшую в связи с общей ситуацией на рынке доткомов. По мере усиления давления инвесторов основатели Google были вынуждены отказаться от своей задекларированный ранее антипатии к рекламе. Вместо этого они решили увеличить рекламный доход, используя свой эксклюзивный доступ к пользовательским данным для генерирования прогнозов кликов пользователей. [5] Реклама Google оказалась более эффективной, чем практически любая другая реклама в Интернете, поскольку она была связана с поисковыми запросами. Поисковые запросы, поставляя информацию о поведении, обеспечили преимущество в качестве таргетирования. Изобретением стало открытие метода продаж этой информации, на основе онлайн-аукциона. Цена за клик стала рассчитываться в соответствии с вероятностью того, что пользователь действительно нажмет на рекламу. [6] В такой системе расчетов рекламодатель по факту начал платить не за показ рекламы, а за переход на свой, рекламируемый ресурс. Естественно, что многие рекламодатели по достоинству оценили новый принцип, и охотно переориентировали свои бюджеты в рекламу на поисковой платформе. Хела Вариана, шефа по экономике Google, называют «Адамом Смитом из Googlenomics» и «крестным отцом» его рекламной модели. Тогдашний генеральный директор, Эрик Шмидт, назвал первое исследование Вариана о рекламных аукционах компании моментом, когда они осознали истинную природу бизнеса Google: «Мы неожиданно осознали, что занимаемся аукционным бизнесом». [7]
Первая модель ценообразования была основана на «кликах», ключевым показателем качества в которой стал коэффициент, прогнозирующий клики пользователей по определенному поисковому запросу. Следующим шагом стало расширение модели за пределы поисковой страницы и превращение всего Интернета в основу целевой рекламы. Эта реклама, таргетируемая на контент, основанная на запатентованных методах Google, получила название AdSense. В компании быстро осознали прогнозирование как точную количественную науку о предсказаниях поведения, назвав ее «физикой кликов». [8] Именно успехи в этой науке стали фундаментом беспрецедентного роста рыночной капитализации компании. Приоритеты реинвестирования Google сместились с простого улучшения услуги в области предоставления информации на создание и институционализацию самой глубокой и технологически продвинутой операции поиска ресурсов таргетинга, которую когда-либо видел мир. Этот поворот ясно отражен в зарегистрированном в 2004г. патенте под недвусмысленном названием «Генерация пользовательской информации для использования в целевой рекламе». [9] Таким образом, Google решил переориентировать свою бизнес-модель, в которой анализ поведения в Интернете, производимый всеми доступными средствами ради рыночного преимущества, вышел на первое место. В этой новой парадигме пользователь больше не был самоцелью, а стал средством достижения целей других людей.

Внедрение новой бизнес модели Google привело к значительному прорыву, который ярко иллюстрируется экономическими показателями. В 2002 году выручка компании выросла до 347 миллионов долларов США, спустя год, в 2003 году поднялась до 1,5 миллиарда долларов США, а еще через год, в 2004 году, когда компания стала публичной, достигла 3,5 миллиардов долларов США. Применение аукционной модели продажи рекламы позволило меньше чем за четыре года увеличить рыночную капитализацию компании на 3950\%. [10] В 2016 году 89\% доходов материнской компании Alphabet приходилось на целевые рекламные программы Google. [11] В 2017 году система обрабатывала в среднем 40000 поисковых запросов в секунду - это более 3,5 миллиардов поисковых запросов в день и 1,2 триллионов поисковых запросов в год. В сентябре 2017 года рыночная стоимость компании оценивалась в 649 млрд. долларов. К началу 2020 года суммарная стоимость акций компании Alphabet (головной компании Google) оценивалась цифрой более 1,2 триллиона долларов США.

Открытие ценности информации о поведении стало критическим поворотным моментом не только в собственной биографии Google, но и для всех глобальных игроков наблюдающего капитализма. Лишь с не- 
большим отставанием новая логика начинает использоваться и крупнейшей социальной сетью Facebook. Генеральному директору Марку Цукербергу было понятно, что миссию компании «соединить каждого со всем миром» невозможно реализовать с помощью услуги, за которую люди должны платить, поэтому компания оказалась перед необходимостью поиска иного способа финансирования. В марте 2008 года Цукерберг принял на работу бывшего исполнительного директора Google Шерил Сэндберг. Примечательно, что в Google она как раз возглавляла развитие новой методологии наблюдающего капитализма, разрабатывая и внедряя ряд инструментов бизнеса онлайн-рекламы. По мнению ее коллег, именно Шерил создала AdWords - платформу бизнес модели Google. [12] Сандберг проницательно разглядела в Facebook социальную сеть, которая была потрясающим источником данных, необходимых для создания системы сбора поведенческой информации. Она хорошо понимала, что благодаря хитрому манипулированию культурой Facebook, ocнованной на близости и общении, можно будет не только использовать информацию о поведении для удовлетворения спроса, но и для его создания. Facebook очень быстро освоил механизм сбора и обработки пользовательского поведения. Особенно сильным инструментом было наличие кнопки «мне нравится», а с 2010 года дальнейшее расширение функционала для целей таргетированной рекламы позволяло передачу в систему социальной сети информации о деятельности из других доменов. [13] Сбор информации о поведении пользователей осуществлялся бесперебойно; акционеры компании были щедро вознаграждены. В 2017 году Financial Times оценила увеличение продаж на 71\%. Информация была подана под заголовком «Facebook: признак истинного величия». С двумя миллиардами активных пользователей в месяц рыночная стоимость компании выросла почти до 500 миллиардов долларов. В первом квартале 2017 года Facebook занимал седьмое место в рейтинге 100 ведущих компаний мира. Еще годом ранее его не было в списке вообще. [14] Во втором квартале 2017 года почти каждый заработанный доллар поступил от рекламы (в большей степени мобильной). Реклама составила 9,2 из 9,3 млрд. [15]

Еще одним ярким примером, в котором роль сбора информации о поведении имеет центральное значение, является облачный цифровой помощник Cortana. Рекламная стратегия, направленная на пользователей программного продукта, выстроена на том, что Cortana знает о пользователе больше, чем он сам. «Я так много знаю о тебе и поэтому могу помочь больше, чем ты ожидаешь. Я вижу паттерны твоего поведения, которых не видишь ты. Вот в чем моя магия». [16] Появление новой операционной системы Microsoft Windows 10 в июле 2015 года показало, насколько серьезно компания относилась к созданию и обеспечению маршрутов по- ставок данных для формирования поведенческой информации. Сбор данных откровенно декларируется в самой бизнесмодели продукта. «Сегодня Cortana знает о вас, вашей компании и окружающем мире. В будущем Cortana узнает все о вашей профессиональной сети и поделится с вами новой идеей развития. Вы всегда на шаг впереди». [17]

Вскоре после открытия модели следящего капитализма, сразу ряд компаний осознал экономический потенциал новой методологии. В первую очередь к сбору поведенческих данных подключились телекоммуникационные и кабельные компании. Постепенно в круг охотников за данными вовлекаются все больше отраслей и участников. Интернет вещей (IoT), индивидуальная медицина, автономное вождение - это лишь некоторые примеры массовой охоты за поведенческими данными. В современном мире наблюдающего капитализма большие данные стало принято называть «новой нефтью» по аналогии с тем, что именно нефть была основой строительства крупного капитала прошлого столетия.

\section{Приншипы следяшего капитализма}

Информация о покупательском поведении с давнего времени использовалась для улучшения и оптимизации продукта. В эпоху массового производства спрос измерялся на основе данных о действиях клиентов. Анализ покупательского поведения определял, производство каких товаров следовало увеличить, а каких, напротив, стоило сократить, и служил источником понимания, какие качества товаров полезны, а какие не востребованы рынком.

С момента, когда технически стало доступно хранение и обработка больших данных, возник потенциал вывода использования поведенческой информации за границы области оптимизации продукта. Применение искусственного интеллекта для обработки больших данных открыло возможности не только всестороннего анализа, но и прогнозирования покупательского поведения. По определению Зубофф, наблюдающий капитализм основан на преобразовании человеческого опыта в данные о поведении, которые декларируются собирающими их компаниями как запатентованные. Из этих данных при помощи искусственного интеллекта изготавливаются прогнозы поведения, которые на вероятностной основе предсказывают, что вы будете делать в будущем. [18] Массовая реализация прогностического продукта потребовала создание рынка нового типа, который Зубофф называет рынком поведенческих фьючерсных контрактов. Экономика быстро отреагировала на появление новой ценности, и капиталистическая система начала стремительно перестраиваться, создавая новые модели, основанные на включении стоимости информации о поведении, в 
свои активы. Собираемые данные стали представлять собой новые средства производства, способные создавать прогностический продукт на основе поведения пользователя. Теперь, собрав, сохранив и обработав эту информацию, из нее можно извлечь предиктивную ценность, основанную на предсказании поведения.

Предлагаемый американской исследовательницей термин «поведенческая прибавка» (Behavioural Surplus) определяется в качестве экономической сущности, обладающей стоимостью, которую сами капиталисты склонны тщательно скрывать. Подобно тому, как во времена становления капиталистической системы марксистский анализ раскрыл суть прибавочной стоимости, современная ситуация требует глубокого осмысления экономической сути поведенческой прибавки и осознания её значения в современном мире. Поведенческая прибавка превратилась в ценный товар, который стал определяющим моментом эпохи следящего капитализма. Модель компании Google основана на сборе «дополнительных данных», которые извлекаются из каждого поиска, производимого в настоящем, анализа следа, оставленного в прошлом и в конструировании прогноза на будущее. Новая модель капиталистического накопления, использует человеческое поведение, а в действительности человеческую природу в качестве сырья. Поведенческая прибавка превратилась в изменяющий всю экономическую игру актив с нулевыми затратами, который переключил приоритет компании с «улучшения качества поиска на беспрецедентно сверхприбыльный рыночный обмен». [18] Основываясь на нулевой себестоимости поведенческой информации, инвестиции логичным образом стали все больше ориентироваться на параметр увеличения количества пользователей. Для реализации этой цели на рынок был выведен широкий спектр «бесплатных» сервисов, благодаря которым уже в скором времени Google оставил своих конкурентов далеко позади. В действительности уровень прибыльности, который стал возможен в Google, после открытия поведенческой прибавочной стоимости, был настолько велик, что привел к фактической монополии в веб-поиске. Таким образом мы можем видеть, как рыночная востребованность прогностического продукта привела к созданию поведенческой стоимости, а бесплатный доступ к сырью, необходимому для создания этого продукта, обеспечил сверхприбыльность и как следствие агрессивный характер роста способов и объемов сбора поведенческих данных.

Охота на поведенческие данные в скором времени достигла беспрецедентного масштаба. Ларри Пейдж, один из основателей Google, описывая перспективы развития IT индустрии, делает акцент на центральной роли сбора информации о поведении. «Люди будут генерировать огромные объемы данных. Все, что вы когда-либо видели, испытывали или слышали, будет доступно для поиска. Вся ваша жизнь будет доступна для поиска». [19]
В эпоху следящего капитализма сбор данных получил новое назначение и стал использоваться в качестве базовой архитектуры извлечения прибыли. Так если Google - это «поисковая компания», то почему она активно инвестирует в устройства для умного дома, индивидуальную медицину и технологии автономного вождения? Если Facebook - это социальная сеть, почему компания работает над разработкой дронов и дополненной реальностью? Такое разнообразие областей инвестирования привлекает внимание наблюдателей, но обычно объясняется как мотивированное ставкой на отдаленное будущее. Однако фактически действия, которые кажутся разнообразными и даже разбросанными по случайному выбору отраслей и проектов, являются одной и той же деятельностью, направленной на одну и ту же цель: захват рынка поведенческих данных. Преследуемая компаниями цель всегда одна и та же: получение информации для извлечения поведенческой прибавочной стоимости. Интересно, что на вопрос, почему Google предлагает линейку из 150 «продуктов», генеральный директор Эрик Шмидт сказал: «Вы можете воспринимать это и как критику, и как стратегию. В действительности целью компании является удовлетворение клиента. Лучший ответ на этот вопрос будет звучать так: у Google есть главный продукт - удовлетворенность клиентов». [20]

Скорее всего, так оно и есть, однако следует учесть, что действительные клиенты компании - клиенты рекламы, которые платят за прогнозы Google. Так как в процессе извлечения поведенческой прибавочной стоимости пользователь выступает всего лишь как средство для поставки данных и не требуется никакой денежной платы за его использование, то главной стратегической целью акторов наблюдающего капитализма становится борьба за монополию пользовательского сырья.

История мобильной операционной системы Android показательный пример борьбы за захват рынка сбора поведенческих данных. Google бесплатно предоставил лицензии платформы Android производителям смартфонов в обмен на предустановку на их устройствах поискового сервиса и других своих приложений. Показательно, что в июле 2018 года компанию обвинили в нарушении антимонопольного законодательства. Еврокомиссия наложила на техногиганта рекордный штраф около 5 млрд. долл. По заявлению еврокомиссара по вопросам конкуренции Маргрет Вестагер (Margrethe Vestager), компания Google использовала платформу Android как инструмент для достижения доминантного положения своей поисковой системы. [21]

\section{Поведенческая парадигма инструментальной власти}

Итак, настоящим продуктом, производимым Google, является не декларируемая компанией услуга поиска 
информации, а результат деятельности, который Google создает в действительности, - предсказания о нашем поведении. Этот товар IT гигант поставляет не нам, а своим реальным клиентам, мы же являемся объектами, из которых Google получает сырье для своих фабрик прогнозирования. Интеллект машины, а следовательно, и качество его предсказаний, напрямую зависит от того, сколько данных он поглощает в процессе обучения. В этом отношении новые средства производства принципиально отличаются от традиционно изготовленного продукта of-line, для которого существует напряжение альтернативы между параметром количества и качества. Сосредоточив ресурс на одном, неизбежно приходится жертвовать другим. Модель наблюдающего капитализма позволяет снять это напряжение, синтезировав оба параметра. Чем большее количество поведенческих данных используется для обучения алгоритмов, тем выше качество предлагаемого продукта. Точная оценка вероятности клика для рекламного объявления оказывает решающее влияние на прибыль от поисковой транзакции. Увеличение точности предсказания всего на доли процента, в таком производстве может принести сотни миллионов долларов дополнительной прибыли. Чем точнее предсказание, тем ниже риск для покупателя и тем выше продажи. В процессе формирования такого продукта пользователь оказывается средством достижения целей других людей. Суть этой модели заключается в том, что прибыль извлекается путем трансформации нашей жизни в поведенческие данные, предназначенные для того, чтобы предсказательные системы могли лучше контролировать нас. С самого начала продукты прогнозирования были в основном направлены на продажу целевой рекламы. Но, как оказалось позднее, реклама была только началом проекта наблюдения, а не целью. Изобретенная Фордом модель массового производства, первоначально примененная в автомобилестроении, очень скоро была использована в других сферах экономики. Точно так же, новая система прогнозирования, разработанная для рекламного бизнеса, оперативно была распространена на целый ряд других доменов IT индустрии.

К. Маркс назвал приватизацию природных ресурсов причиной, которая привела к «первоначальному накоплению капитала». [22] По аналогии с присвоением природных ресурсов приватизация поведенческой стоимости приводит к концентрации капитала в цифровую эпоху. Человеческий опыт, осознанный в качестве «поведения», отчуждается от источника, его производящего, и присваивается при помощи механизма, конституируемого наблюдающим капитализмом. Знание, авторитет и власть консолидируются в руках собирающих поведенческую информацию компаний, для которых пользователь является лишь ресурсом, производящим данные. Результатом этой концентрации является то, что наблюдающий капитал, приобретая все больше возмож- ностей, использует находящиеся под его контролем автоматизированные машинные процессы не только для прогнозирования пользовательского поведения, но и, в конечном итоге, для его формирования. Масштаб сбора поведенческих данных претерпевает значительный сдвиг от фиксации пользовательской веб-активности к сканированию всего жизненного пространства человека. Без такого расширения масштаба, например, уже немыслимо конкурентное развитие технологий интернета вещей или области индивидуальной медицины.

Архитектура повсеместного мониторинга становится хорошо оснащенной системой для широкомасштабного вмешательства во все сферы человеческой жизни. Именно в связи с активацией техник поведенческого анализа и применением машинного обучения с так называемыми технологиями подталкивания можно говорить о слиянии методологий обработки данных и поведенческих наук. Теория подталкивания - это концепция поведенческой экономики, которая была придумана экономистом Ричардом Талером и ученым-правоведом Кассом Санстейном и описана в изданной в 2008 г. книге «Nudge. Как улучшить наши решения о здоровье, благосостоянии и счастье» (Improving Decisions About Health, Wealth, and Happiness). Под подталкиванием понимают метод влияния на поведение людей, не прибегая к ограничениям и возможностям выбора. Подталкивание направлено на формирование решения, которое спроектировано внешним воздействием и не является волеизъявлением самого индивидуума. [23] Реалии сегодняшнего дня таковы, что специалисты в области обработки данных, работающие над решением задач, связанных с экономикой действий, считают вполне допустимым овладение искусством цифрового подталкивания во имя коммерческих интересов своей компании. Этические претензии в адрес механизма подталкивания в доцифровую эпоху обычно отклонялись по причине их патерналистских намерений. Авторы теории подталкивания высказывались за так называемый «либертарианский патернализм», сочетавший методологию классического патернализма с идеями либерализма. В целом признавалось, что подталкивание через подсознание человека манипулировало его поведением, но делалось это во имя блага самого человека, обеспечивая ему более долгую и безопасную жизнь. [24]

В эпоху следящего капитализма подталкивание может принимать гораздо более зловещую форму. Не регулируемое законодательно и не контролируемое правительством, встроенное в сложную архитектуру алгоритмического кода интеллектуальных устройств, подталкивание становится основой для создания новой науки о крупномасштабной модификации человеческого поведения. [25] Вооружённая машинным интеллектом технология подталкивания представляют собой гораздо более могущественную силу для манипулирования 
поведением в политических, социальных и экономических интересах, чем в доцифровую эпоху.

Несмотря на то, что наблюдающий капитализм нацелен на контроль и модификацию человеческого поведения, было бы неверным отождествлять его с тоталитарными режимами 20-го века. Тоталитарная власть реализуется с помощью непосредственного прямого давления на личность. Внутренняя жизнь каждого формируется постоянной, персонифицированной угрозой наказания. Анонимного, скрытого воздействия недостаточно для перманентного поддержания атмосферы страха, которая является базовым условием осуществления тоталитарного правления. Напротив, наблюдающий капитализм не интересуется нашими сознательными представлениями о власти, не обладает желанием участвовать в трудоемком стиле правления, основанном на формировании дисциплинарного страха, характерном для тоталитарных режимов.

В отсутствие исторического прецедента Зубофф развивает понятие инструментальной власти, суть которой заключается в «использовании поведения в качестве инструмента для достижения целей модификации, монетизации и контроля». [26] Поведение человека становится все более важным знанием, которое инструментальная власть использует для наиболее эффективного решения задачи прогнозирования. Парадигма поведенческих наук, поставившая перед собой задачу преобразовать скрытое естество человеческого желания в научный факт, была предложена бихевиоризмом. Этот эпистемологический режим был выявлен достаточно давно, однако новые технологии позволили сделать применение этой парадигмы заметно более эффективным. Одним из влиятельнейших представителей этого направления является американский ученый Беррес Фредерик Скиннер. Вместо объяснений поведения человека на основе индивидуальных процессов Скиннер предложил интерпретировать действие человека как функционально зависимое от наблюдаемых внешних раздражителей. Разработанная им методология перевела исследование поведения из разряда гипотетических теорий в разряд эмпирически подтвержденных, научно обоснованных экспериментов. Поведение можно предсказать и контролировать при помощи организации среды, в которую вовлечен организм. При этом нет необходимости изучения внутренних механизмов, которые не поддаются выявлению в результате эксперимента. С точки зрения Скиннера, идеи свободы и автономии являются в определенном смысле «вводящими в заблуждение». [26] Они якобы ложно связывают поведение человека с организующим влиянием внутреннего мира. В бихевиористском подходе методология влияния на индивидуум смещается от стратегии построения человеческого духа к стремлению формирования его действия. При установлении инструментальной власти это определяет переход государственной политики, нацеленной на утверждение индивидуальной свободы и ответственности, к политике, более узко ориентированной на изменение внешнего проявления.

С приходом возможности широкомасштабного использования поведенческих данных уходят в прошлое старые теории, построенные на методологии поиска причин, объясняющих почему что-то может или не может произойти. Им на смену приходят новые методы, предсказывающие то, как люди будут действовать. Теперь становится неважным, какие именно причины вызывают эти действия, важно, что возникает возможность предсказать их исход с небывало высокой степенью точности. [27]

Крис Андерсон, главный редактор издания Wired, в известном размышлении о «Конце теории» в 2008 году высказался о влиянии прикладной математики Google на большие поведенческие данные: «Каждой теории, касающейся человеческого поведения, от лингвистики до социологии, следует забыть таксономию, онтологию и психологию. Важно не то, почему люди делают то, что делают. Важно то, что появилась возможность отслеживать, измерять и предсказывать то, что они будут делать с беспрецедентной точностью». [26]

В доцифровую эпоху отсутствие инструментов, позволяющих осуществить контроль и обработку социально-экономической действительности, заставляло правительства действовать в русле неолиберального мировоззрения, используя рынки для обеспечения устойчивого функционирования. Поскольку участники только свободного рынка могли позволить ему функционировать так, как он должен, свобода становилась залогом экономического успеха и стабильности. Успех инструментальной власти опирается на факт, что она действует в режиме стабильности. Опасность заключается в том, что теперь стабильность не обязательно обеспечивается наличием либеральных рынков, основанных на свободе. Свобода перестает быть гарантом устойчивой экономики. Данных, собираемых наблюдающими капиталистами, может оказаться вполне достаточно для того, чтобы предсказания поведения обеспечили бесперебойную работу экономической системы. Может показаться, что инструментализм представляет собой гораздо меньшую угрозу либеральным ценностям и социальным институтам, чем цифровой тоталитаризм, появляющийся, например, в современном Китае. Однако, несмотря на его очевидную совместимость с либеральными нормами, инструментализм разрушает демократию изнутри, пожирая человеческие возможности и самопонимание, необходимые для поддержания демократической жизни. Тем самым, его обманчивая невинность может представлять собой дополнительную опасность. 


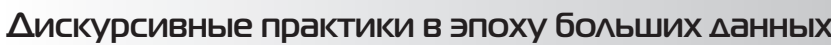

Следует отметить, что угроза демократическим институтам, исходящая от применения технологий, усматривалась и в доцифровую эпоху. Критический анализ, предпринятый М. Хоркхаймером и Т. Адорно [29] и в особенности Г. Маркузе, [30] вскрыли механизмы деструктивного действия технического прогресса на общество. В процессе модернизации одним из важных механизмов, способствующих сохранению демократического общества, по мнению Ю. Хабермаса, должно стать обеспечение открытого публичного пространства, формируемого дискурсивными практиками. [31] В этой связи целесообразно рассмотреть, какое влияние на формирование таких практик оказывает следящий капитализм.

Начнем с того, что рассмотрим вопрос с теоретической точки зрения. Наблюдающий капитализм основан на поиске паттернов поведения и использовании их для прогнозирования дальнейших действий. Если полученное таким методом описание является лишь упрощенно-редуцированной версией поведения человека, в реальности действующего иррационально, то возникает вопрос, насколько это предсказание может быть успешным в процессе формирования поведения путем внешнего влияния? В данном случае можно говорить о так называемом поведенческом парадоксе: если человеческая природа изначально непредсказуема, то как удается свести поведение человека к управлению машинным интеллектом? Применительно к технологии сбора поведенческой информации это выглядит следующим образом. Как только человеку становится известен факт предсказания, возникает новая ситуация, не сводимая к совокупному объему данных, собранных на основе предыдущего поведения. Перед человеком предстает новый список фактов, и его реакция остается открытой для выбора. Поэтому для успешной манипуляции поведением, факт предсказания должен быть выведен из-под осознанного внимания индивидуума, а внешнее воздействие должно оказываться через подсознательный канал восприятия. Становится еще более понятным стремление следящих IT платформ организовать систему наблюдения таким образом, чтобы исключить вовлечение критического осознания самих наблюдаемых. Ведь в противном случае, прогностический эффект, скорее всего, будет сведен к нулю.

Рассматривая вопрос о формировании дискурсивных практик с практической стороны, прежде всего стоит обратить внимание на фактор скорости развертывания следящего капитализма. Цифровое господство, изменяя весь знакомый уклад вещей, устанавливается с опережением еще до того, как у нас появилась возможность обдумать и принять решение. Небывалая скорость развития технологий сбора и обработки поведенческих данных открывает необычный формат прикладного утопизма. В отличие от его традиционной версии, когда между теоретической декларацией утопии и ее практическим воплощением существует временной промежуток, позволяющий сформироваться критическому дискурсу и разностороннему осознанию. Техники наблюдающего капитализма имеют тенденцию быть развернутыми, прежде чем в обществе возникнет социальное понимание последствий их применения.

Таким образом, реализация дискурсивных практик в процессе развития цифровых технологий осложнена по меньшей мере двумя причинами:

Во-первых, дискурсивные практики основаны на информированности и вовлеченности всех сторон в предмет дискурса. В случае цифровых технологий эффект асимметрии распределения знания приводит к затруднению установления дискурсов, построенных на коммуникативном действии. Вместо этого коммуникативное действие замещается стратегическим, при этом логика понимания уступает логике эффективности, которая при необходимости может оправдывать и применение механизмов манипулирования. [32]

Во-вторых, сказывается фактор скорости развития цифровых технологий. Дискурсивные практики, построенные на коммуникативном действии, реализуются со скоростью овладения человеком сути и понимания предмета, в отличие от сверхскоростей, которые характерны для разворачивания современных методов обработки данных.

В целом можно отметить, что опасность инструментализации жизненного мира, описанная Хабермасом в контексте критической оценки влияния технологий на современное общество, имеет место и в цифровую эпоху. Эту критику, безусловно, следует распространить и на технологии обработки поведенческих данных, с той разницей, что с приходом наблюдающего капитализма эффект от негативных последствий становится еще более угрожающим.

\section{ЛИТЕРАТУРА}

1. Корпоративная информация Google. [Электронный ресурс] - Режим доступа: https://about.google/int//ALL_ru/.

2. Shoshana Zuboff. Das Zeitalter des Überwachungs-Kapitalismus. 2018. Campus Verlag GmbH Franfurkt New York. ISBN 978-3-593-50930-3. Die amerikanische Ausgabe: The Age of Surveillance Capitalism. The Fight for a Human Future at the New Frontier of Power. 2019 bei Public Affairs, New York.

3. Joachim Hirsch, Roland Roth: Das neue Gesicht des Kapitalismus. Vom Fordismus zum Post-Fordismus. VSA, Hamburg 1986. 
4. FORD MODEL T STARS IN THE DESIGN MUSEUM TANK. [Электронный ресурс] - Режим доступа: https://www.carpages.co.uk/ford/ford-model-t-07-04-08.asp

5. The Guardian. J.Naughton. [Электронный ресурс] - Режим доступа: https://www.theguardian.com/technology/2019/jan/20/shoshana-zuboff-age-ofsurveillance-capitalism-google-facebook

6. Peter Coy. The Secret To Google's Success [Электронный ресурс] - Режим доступа: https://www.bloomberg.com/news/articles/2006-03-05/the-secret-togoogles-success

7. Steven Levy, Secret of Googlenomics: Data-Fueled Recipe Brews Profitability. [Электронный ресурс] - Режим доступа: https://www.wired.com/2009/05/nepgooglenomics/

8. Interview Eric Schmidt end Jonathan Rosenberg, How Google Works [Электронный ресурс] - Режим доступа: https://www.youtube.com/watch?v=3tNpYpcU5s 4\&feature $=$ youtu.be\&t $=3287$

9. Generating user information for use in targeted advertising. [Электронный ресурс] - Режим доступа: https://patentimages.storage.googleapis.com/3a/d3/ a0/6a40089c5bc051/CA2552181A1.pdf

10. Amendment No. 9 to Form S-1 Registration Statement Under the Securities Act of 1933 for Google Inc.«, Securities and Exchange Commission, 18. August 2004. [Электронный ресурс] - Режим доступа: https://www.sec.gov/Archives/edgar/data/1288776/000119312512025336/d260164d10k.htm

11. Selected Financial Data for Alphabet Inc.", Form 10-K, Commission File, United States Securities and Exchange Commission, 31. Dezember 2016 [Электронный ресурс] - Режим доступа: https://www.sec.gov/Archives/edgar/data/1652044/000165204417000008/goog10-kq42016.htm

12. David Kirkpatrick, The Facebook Effect: The Inside Story of the Company That Is Connecting the World. New York: Simon \& Schuster, 2011. S.257.

13. W02011097624 - Communicating Information In A Social Network System About Activities From Another Domain. [Электронный ресурс] - Режим доступа: https://patentscope.wipo.int/search/en/detail.jsf?docld=W02011097624\&tab=PCTBIBLI0

14. Global Top 100 Companies by market capitalisation 31 March 2016 update. [Электронный ресурс] - Режим доступа: https://www.pwc.com/gr/en/publications/ assets/global-top-100-companies-by-market-capitalisation.pdf

15. MENLO PARK, Calif., Feb. 1, 2017 /PRNewswire/ -- Facebook, Inc. (NASDAQ: FB) today reported financial results for the fourth quarter and full year ended December 31, 2016. [Электронный ресурс] - Режим доступа: https://investor.fb.com/investor-news/press-release-details/2017/Facebook-Reports-Fourth-Quarter-andFull-Year-2016-Results/default.aspx

16. Here's What Really Makes Microsoft's Cortana So Amazing [Электронный ресурс] - Режим доступа: https://time.com/3960670/windows-10-cortana/

17. Microsoft Linkedln Conference Call Chris Suh, Satya Nadella, JeffWeiner, Amy Hood, Brad SmithMonday, June 13, 2016. [Электронный ресурс] - Режим доступа: https://www.microsoft.com/en-us/Investor/events/FY-2016/microsoft-linkedln.aspx

18. Shoshana Zuboff. Das Zeitalter des Überwachungs-Kapitalismus. 2018. Campus Verlag GmbH Franfurkt New York. S.23

19. Douglas Edwards. I'm Feeling Lucky: The Confessions of Google Employee Number 59. 432 pages Published 2011 by Houghton Mifflin Harcourt. P. 339.

20. Ken Auletta, Googled: The End of the World as We Know It. New York: Penguin, 2010, Kindle, P.1105-1113

21. Экономическая правда. Монополист Google: можно ли спрятаться? [Электронный ресурс] - Режим доступа: https://www.epravda.com.ua/rus/publicatio ns/2018/07/27/639078/

22. Karl Marx, Das Kapital: Kritik der politischen Ökonomie. Karl Marx, Friedrich Engels, Werke, Bd. 23. Berlin: Dietz, 1962. S. $777 f f$.

23. Richard Thaler, Cass Sunstein: Improving decisions about health, wealth and happiness. Yale University Press. 2008, 304 P. P. 6.

24. Rhys Jones, Jessic Pykett, Mark Whitehead. Changing Behaviours: On the Rise of the Psychological State. Edward Elgar. 2013, 232 P.

25. Shoshana Zuboff. Das Zeitalter des Überwachungs-Kapitalismus. 2018. Campus Verlag GmbH Franfurkt New York. S.335

26. Skinner B.F. Beyond Freedom and Dignity. London: Jonathan Cape.1972. 240 Pages.

27. Pentland, Alex, Social Physics: How Good Ideas Spread-the Lessons from a New Science, New York, NY: The Penguin Press, 2014. 320 Pages.

28. Anderson C. The end of theory: The data deluge makes the scientific method obsolete. Wired. 2008. [Электронный ресурс] - Режим доступа: https://www.wired. com/2008/06/pb-theory/

29. Max Horkheimer, Theodor W. Adorno. Dialektik der Aufklärung. Philosophische Fragmente. Fischer.1988. 288 Seiten.

30. Herbert Marcuse. Der eindimensionale Mensch: Studien zur Ideologie der fortgeschrittenen Industriegesellschaft. Klampen \& Johannes GbR. 2014. 296 Seiten.

31. Jürgen Habermas. Vorstudien und Ergänzungen zur Theorie des kommunikativen Handelns. Suhrkamp Taschenbuch.1995. 607 Seiten S 130.

32. Климович А.П. Рационализация модернизирующихся обществ и дискурсивные практики нормативного регулирования. Вестник Воронежского государственного Университета Серия: Философия, 2019, № 3, Июль - Сентябрь. С. 11 http://www.vestnik.vsu.ru/pdf/phylosophy/2019/03/2019-03-01.pdf

(с Климович Александр Павлович (allexgut@gmail.com).

Журнал «Современная наука: актуальные проблемы теории и практики» 